\title{
Caring for someone with high-grade glioma: a time of rapid change for caregivers
}

Palliative Medicine

$0(00)$ I-7

(C) The Author(s), 2010.

Reprints and permissions:

sagepub.co.uk/journalsPermissions.nav

DOI: I0.1I77/0269216309360II8

pmj.sagepub.com Ruth McConigley Curtin University of Technology, Western Australian Centre for Cancer and Palliative Care, Perth, Australia
Georgia Halkett Curtin University of Technology, Western Australian Centre for Cancer and Palliative Care, Perth, Australia
Elizabeth Lobb Curtin University of Technology, Western Australian Centre for Cancer and Palliative Care, Perth, Australia; Calvary Health Care
Sydney and the Cunningham Centre for Palliative Care, Sydney, Australia

Anna Nowak University of Western Australia, School of Medicine and Pharmacology, Perth, Australia

\begin{abstract}
Patients diagnosed with high-grade gliomas have a poor prognosis and limited life expectancy, and often experience rapid decline in function. Caring for a patient with high-grade glioma is particularly stressful because caregivers are faced not only with cancer-related caregiving issues, but also issues relating to caring for someone with cognitive impairment. This study aimed to articulate the experiences of family caregivers of people diagnosed with high-grade glioma and to describe their information and support needs. A grounded theory method was adopted. Twenty-one family caregivers of people with high-grade glioma were interviewed using a semi-structured interview guide. A constant comparison method of data analysis was employed. A central theme, A Time of Rapid Change and two sub-themes, Renegotiating Relationships and Learning to be a Caregiver, emerged to describe the experiences of participants. Caregiving was characterized by numerous role and life changes from the moment of diagnosis. Caregivers in this study reported experiences similar to those described by caregivers of people with other cancers. What differed for this group was the rapidity of change and the need for immediate information and support to assist with caring for a person with high-grade glioma.
\end{abstract}

\section{Keywords}

caregivers, grounded theory, high-grade glioma

\section{Introduction}

Malignant high-grade gliomas (HGGs) are the most common primary brain tumours in adults $(80-85 \%$ of all brain tumours), and have a median survival ranging from less than 1 year to 3 years from diagnosis. ${ }^{1}$ The aim of treatment is to increase survival time rather than to cure patients. ${ }^{2}$ Most patients with $\mathrm{HGG}$ are no longer able to drive, work, or perform at their normal fitness levels, and some have significant cognitive and physical disabilities. ${ }^{3}$ Seizures and personality changes are common and pose particular difficulties for patients and their families. ${ }^{4}$ Two reviews of the literature relating to care of patients and families with HGG have found there is limited information about the needs of this group; however, current literature suggests that they have different experiences to those with other types of tumours. ${ }^{5,6}$ The cognitive changes and, in particular, personality changes associated with HGG lead to changes in family roles and relationships that are not regularly seen with other cancers.

Sherwood and colleagues suggest that family caregivers of people with HGG may experience more role strain than other family caregivers because they have to cope with cancer-related caregiving issues and also neurological changes that characterize $\mathrm{HGG}^{7}$ Schmer and colleagues postulate that the diagnosis of a brain tumour is particularly stressful for caregivers because the prognosis is dire and life expectancy is short. ${ }^{8}$ It is therefore unsurprising that these caregivers report

\section{Corresponding author:}

Ruth McConigley, GPO Box U1987, Perth, Western Australia, Australia 6845.

Email: r.mcconigley@curtin.edu.au 
increased stress levels ${ }^{9}$ and decreased quality of life. ${ }^{10,11}$ Family members describe having a brain tumour as unique among cancer diagnoses because of the cognitive changes that may occur from diagnosis or even earlier and lead to increased stress and caregiver burden. ${ }^{12}$ Furthermore, caregivers of people who die soon after diagnosis have been reported to experience greater levels of depression than those caring for people with a long illness trajectory. ${ }^{13}$ It is therefore likely that family caregivers of people with HGG have experiences that differ from other caregivers of people with cancer, in that they face unique care-related issues and a shorter disease trajectory than caregivers for people with other cancer diagnoses.

This study aimed to articulate the experiences of family caregivers of people diagnosed with HGG and to describe their information and support needs.

\section{Methods}

The study employed an emergent qualitative design, using theoretical and procedural direction from grounded theory research. ${ }^{14}$ Semi-structured interviews were used to elicit information about caregivers' experiences and their information and support needs. A semi-structured interview, based on relevant literature, expert knowledge and clinical experience was used to elicit information about the family caregiver's experiences and their information and support needs. The opening interview question was intended to act as a 'grand tour' question: ${ }^{15}$ We are interested in understanding how you are managing with caring for someone who has been diagnosed with a brain cancer. Would you like to tell me about some of your experiences? General questions and prompts for specific items were used to encourage further disclosure, thus comprising the 'mini tour'. Grounded theory entails simultaneous data collection and analysis, together with systematic efforts to check and refine developing data categories. ${ }^{14}$ The ongoing process of data collection and analysis informed the interview questions. Hence, in addition to the research questions formulated at the outset, other avenues of investigation emerged during data collection.

Family caregivers of patients with $\mathrm{HGG}$ were recruited from the medical oncology department of a tertiary referral centre for neurological cancers. Family caregivers were defined as the person named by the patient as the individual most involved in his/her care. Inclusion criteria were: providing care for someone diagnosed with a Grade III-IV HGG within the last year, 18 years of age or older, and conversant in English.

Purposive sampling was used to identify patients and caregivers with differing clinical and social variables.
We aimed to identify caregivers who were caring for people at different stages of their illness (e.g. during chemo-radiotherapy, adjuvant chemotherapy or at disease recurrence), different ages, gender, geographic location and family situation to sample a broad representation of caregiving experiences.

Ethics approval was gained from Curtin University of Technology and the tertiary hospital involved in recruiting participants.

\section{Data analysis}

Interviews were tape recorded and transcribed verbatim. Transcripts were managed using QSR N7 software. Data were analysed using a constant comparison method. ${ }^{14}$ Open, axial and selective coding was used to analyse the data. Open coding involved repeated reading of the interview transcripts and the development of codes describing key points. Axial coding was used to develop aggregate codes and develop concepts. Selective coding was then used to link data together and develop the central theme and subthemes.

\section{Results}

Overall, 21 caregivers were interviewed, nine alone and the remaining 12 with the patient present. Twenty of the caregivers were a spouse who lived with the patient, and the remaining caregiver was a parent who did not live with the patient. Carers were interviewed at different time points in the patient's disease trajectory corresponding with specific treatment regimens. The demographic characteristics of the sample are presented in Table 1. Information about the patients the participants were providing care for is presented in Table 2 .

The central theme that emerged to describe the caregivers' experiences was A Time of Rapid Change. Two sub-themes related to this theme were identified: Renegotiating Relationships and Learning to be a Caregiver.

\section{A time of rapid change}

The experiences of caregivers were characterized by rapid changes that occurred from the moment of diagnosis and throughout the patient's illness. Many were given a specific timeframe relating to the patient's impending death. One caregiver described receiving the prognosis:

\footnotetext{
... She [ the doctor] said 'we've got the results of the test on the tumour' and she said 'it's aggressive brain tumour', and she put her fingers she said, 'one, two, three, it's in the fourth stage' and she said 'that's not very good' and
} 
Table I. Demographic characteristics of study participants $(n=2 \mathrm{I})$

\begin{tabular}{|c|c|}
\hline & $N(\%)$ \\
\hline \multicolumn{2}{|l|}{ Gender } \\
\hline Male & $4(19)$ \\
\hline Female & $17(8 \mathrm{I})$ \\
\hline \multicolumn{2}{|l|}{ Age range (years) } \\
\hline $30-39$ & $2(9.5)$ \\
\hline $40-49$ & $2(9.5)$ \\
\hline $50-59$ & $10(47.6)$ \\
\hline $60-69$ & $6(28.6)$ \\
\hline $70+$ & I (4.8) \\
\hline \multicolumn{2}{|l|}{ Relationship to patient } \\
\hline Spouse/partner & $20(95.2)$ \\
\hline Parent & I (4.8) \\
\hline \multicolumn{2}{|l|}{ Employment status } \\
\hline Full-time employment & $4(19)$ \\
\hline Part-time employment & $3(14.3)$ \\
\hline Not employed & II (52.4) \\
\hline $\begin{array}{l}\text { Employed with changed conditions } \\
\text { relating to caregiver responsibilities }\end{array}$ & $3(14.3)$ \\
\hline \multicolumn{2}{|l|}{ Caring status } \\
\hline Also caring for dependant children & $6(28.6)$ \\
\hline Not caring for anyone else & $13(61.9)$ \\
\hline Information not available & $2(9.5)$ \\
\hline \multicolumn{2}{|l|}{ Geographical location } \\
\hline Rural Western Australia & $5(23.8)$ \\
\hline Metropolitan area (Perth) & $16(76.2)$ \\
\hline
\end{tabular}

she said 'we'll give you between six to twelve months'.

I was stunned, shocked (C018).

Brain surgery bought immediate change to the patient's condition, often causing changes to function and cognition. The diagnosis also brought with it what the caregivers considered a change of role - their partner had become a patient with a brain tumour. One caregiver explained:

Oh no, it was really hard, you know emotional and highlights the fact that you haven't prepared for anything like that in your life. I was only 38 or 39 and you don't sort of think about dying (C003).

A major change for caregivers at the time of diagnosis, surgery and treatment was the move into a substantive caregiver role immediately after surgery. One participant explained:

The social worker said, 'You know, there's got to be someone that's got to look after him' and being
Table 2. Demographic characteristics of patients $(n=21)$

\begin{tabular}{lr}
\hline & $N(\%)$ \\
\hline Gender & $16(76.2)$ \\
Male & $5(23.8)$ \\
Female & \\
Age range (years) & $1(4.8)$ \\
$30-39$ & $3(14.3)$ \\
$40-49$ & $9(42.8)$ \\
$50-59$ & $5(23.8)$ \\
$60-69$ & $2(9.5)$ \\
$70+$ & $1(4.8)$ \\
Missing data & \\
Diagnosis & $3(14.3)$ \\
Astrocytoma Grade 3-4 & $18(85.7)$ \\
Glioblastoma multiforme & \\
Patient status & $7(33.3)$ \\
$6-8$ weeks post-diagnosis, undergoing \\
combined chemotherapy/radiotherapy \\
5-6 months post-diagnosis, undergoing \\
adjuvant chemotherapy \\
$9-12$ months post-diagnosis, first line \\
treatment completed
\end{tabular}

the wife, I said 'I have to do it don't I?' and I did (C018).

Caregivers who were employed needed to make decisions about whether they could combine caregiving and work. One caregiver said:

Well I did not go back to work fulltime, I was doing ten hours a week, you know. So the rest of the days I was home with him (C018).

After surgery patients were not able to drive, and this led to a time-consuming new task for caregivers driving to frequent medical appointments. The role of driver was particularly stressful for female caregivers who previously drove less often. One caregiver explained:

I haven't ever driven in the city before... 'cause my husband always had driven and it was a big thing to take off and drive down there because he wasn't able to drive (C020).

Caregivers and patients also needed to make plans for the future and reassess priorities, knowing that life expectancy was unpredictable. One caregiver said:

You have to think about what we do now is different than what we would've done before. Whether we have more 
children, and we both wanted to have lots of children. Now I'm thinking it might not be a wise thing to do (C007).

The rapid changes occurring at the time of diagnosis and surgery meant that caregivers needed immediate access to information about practical matters so that they could begin to make new plans and reorder their lives. One caregiver described her needs in response to the very short prognosis communicated by medical staff:

I needed more the practical stuff, what do we do? What should we expect? When we went to see the neurosurgeon, he gave us a very short time span and was talking about bringing [our son's] wedding forward, like the wedding was in six weeks and that was really quite scary (C008).

The diagnosis of HGG led to rapid changes in many facets of the lives of caregivers. The two sub-themes relate to specific areas that changed for caregivers: relationships and the need to quickly learn how to provide care.

\section{Renegotiating relationships}

For many couples there was a change in their relationship and roles following diagnosis. One caregiver explained:

I think things change dramatically and you've gotta do everything that normally your wife used to do but we're getting there (CO01).

In particular, caregivers had to adapt to a new relationship that was quite different from the pre-diagnosis relationship. Their partner was no longer able to contribute intellectually and physically as before, and the caregiver had to take on many new responsibilities. One caregiver said:

Everything was partnership and now it's not and it's very hard to get used to (CO21).

Caregivers found that because of the patients' cognitive changes and communication difficulties they needed to take on a decision-making role for their partner. They made decisions about treatment, practical needs, finances and many other issues. One caregiver explained:

I need to make the decisions myself as far as the doctor goes, I'm the head caregiver (C001).
Caregivers were also faced with questions regarding the care to be provided and quality of life, particularly because treatment was not curative:

You have to make a decision whether you're going to extend life or extend death, oh no, prolong life or prolong death (C008).

Taking on the role of decision-making at such an emotionally charged time was stressful for some caregivers. One caregiver, when asked whether she made a lot of decisions, replied:

Too many. Too many because then you're left wishing in your heart have I made the right decision, am I doing the right thing (C009).

Caregivers also took on a role of 'interpreter' and advocate when the patient was not able to make their wishes known:

'Cause my husband really can't make himself understood at times and other times he can. But it's very frustrating when he can't speak and use words, and he puts in all the wrong words (C024). ${ }^{16}$

\section{Learning to be a caregiver}

The effects of brain surgery, particularly changes to physical functioning, meant that family members needed to provide care immediately after surgery. Caregivers stated that they felt poorly prepared for the new role:

\section{But it's a big learning curve and it happened so quickly and that's the thing which I found was hard and though people kept trying to help we couldn't get the information that was really needed. You had to learn as you go along (C001).}

Caregivers sought information about how to provide care and about what to expect. Information was difficult to obtain because they did not know what questions to ask or where to look for information:

The thing about it is that the information ... the abstract of not knowing where you're going, what's happening... most of the time... and that's the thing that I find a bit confronting sometimes (COO1).

Caregivers needed to learn how to provide personal care such as showering, toileting and dressing:

Well I've had to shower her... When she first came out of hospital she couldn't move much. She was paralysed 
down the left hand side so it was very difficult. I had to get her into a commode type chair, put her into the bathroom, get her from the commode to the sliding down chair (C001).

Most patients needed to take medication, but cognitive changes meant that they were not always able to manage their own medications. One caregiver explained:

And also the responsibility of being a watchful eye with him because even like the medicine I have to measure it all out for him. If you put it beside his bedside cabinet and put it there for after the meal it doesn't mean to say he's going to take it (CO24).

The nature of the disease progression was a shock for caregivers. Many described fear of seizures as being ever-present. However, caregivers often felt inadequately prepared to manage a seizure and required extra support and information about this aspect of the illness. One caregiver said:

When I'm away I worry about what's going on with him. I won't let him go around the block without his mobile and I ring him to check that he's alright... Yes and I'm frightened of that for myself too, because I don't know that I'm going to do the right things (C009).

Another caregiver explained that the fear of seizures also impacted on what activities they encouraged their partners to participate in:

I can't think of an activity that suits him. I mean apart from maybe taking him to the pool and keep him in the shallow part, you know, in case something goes wrong. It's hard to find something that he can do (C003).

Caregivers were generally cognizant of the need to care for themselves while they were in the caring role, though many found this difficult to achieve. One said:

Yeah and then you neglect yourself too, like you don't know all those things that you should do. Like go to doctors yourself ( $\mathrm{COO3}$ ).

Knowing where to get support when required was also difficult. Many caregivers turned to friends and family for support:

We've got good friends too that have had cancer in their family too. They are really great they come and you know, the couple of times he has had seizures my daughter has come over and they've come straight over (C003).
The caregiving role was stressful and relentless, but many caregivers expressed reluctance to leave the patient because of fear of seizures which others could not manage, and a reluctance to ask for help. However, some caregivers needed time away from the patient, either to attend to practical matters such as shopping or to have some 'time out':

I don't actually call out for help as much as I should. It would probably do me good to actually have a break where I can have [a friend] or someone come and be with [husband] for the day and maybe go and buy some clothes or something. 'Cause I take him everywhere with me for that fact that he's a seizure risk and that two times he's hit his head and bled (C024).

Few of the caregivers had accessed formal respite services.

\section{Discussion}

In general, the difficulties reported by participants in this study were similar to those described by caregivers of people with other cancers. Stress at diagnosis of a life-limiting illness and throughout the disease trajectory is frequently reported in the caregiver literature. $^{8,9,17,18}$ Relationship changes, family upheaval and changes in employment status are also reported as being common. ${ }^{8,19-21}$ Many caregivers in the current study experienced changes in their lifestyle and took on multiple roles, such as caregiving, outside employment and caring for children. Several authors have reported that these experiences lead to increased stress levels. ${ }^{18,21,22}$

What was different for these caregivers was the rapidity with which the changes took place. For most, the transition into the caregiver role began abruptly with diagnosis followed quickly by brain surgery. After surgery, patients were unable to continue driving and many had physical and cognitive changes that meant they required intensive care from this period, which is earlier than most people with cancer. The suddenness of transition into the caregiver role was compounded by the short prognosis of HGG and the frankness of medical staff about this poor prognosis. The knowledge that the stressful and time-consuming treatment regime was palliative only is likely to have contributed to stress experienced by this group.

The findings of this study are consistent with others that have underscored the need for caregivers of people with HGG to have supports available from diagnosis. $^{10}$ In particular, caregivers required practical information to assist their transition into the caregiver role. Information about $\mathrm{HGG}$ and the care required should be readily available to caregivers. However, the 
information needs of caregivers are emergent ${ }^{23}$ and it is therefore essential that the provision of information is staged to allow them to adapt to new concepts before more are introduced. ${ }^{24}$ Health professionals could play a larger role in providing opportunistic caregiver education; for example, pharmacists could offer education about medication management, and physiotherapists could assist in teaching skills relating to providing physical care. Education regarding seizure management is critical for those who care for these patients. Cashman and colleagues demonstrated that a targeted education programme was beneficial for family caregivers of people with $\mathrm{HGG}$ and increased their understanding of the disease and the care required by patients. ${ }^{25}$

This study also highlights the need to ensure that practical supports are available for these caregivers. Participants were reluctant to access outside help from people unfamiliar with the patient because of their fear of the patient having a seizure, and they worried that patients would not be able to adequately communicate with others. Sherwood and colleagues suggest that health professionals can take the lead in helping caregivers feel comfortable delegating tasks to others, thereby reducing the burden of care. ${ }^{7}$ It is also essential that support services be made available by healthcare providers. The provision of respite by people experienced in the care of patients with $\mathrm{HGG}$ and explicitly competent in seizure first aid, either in the home or inpatient setting, would assist in alleviating fear of leaving the patient. There is limited evidence of the efficacy of different support services in minimizing caregiver burden. There is a suggestion that brain tumour specialist nurses may offer extra support and reassurance to patients and families ${ }^{26,27}$ Curren found that a telephone support line manned by a specialist nurse was able to provide much-needed information and support to patients and families. ${ }^{28}$

Health professionals can also support caregivers of people with $\mathrm{HGG}$ in their decision-making role. Greaves and colleagues found that caregivers want support in making decisions if the patient becomes cognitively impaired, and found that caregivers suffered feelings of guilt and uncertainty if they were not supported during decision-making. ${ }^{29}$ The primary care and neuro-oncology teams involved with diagnosis of HGG are ideally placed to initiate discussion with patients and caregivers about end-of-life issues. While it is essential that discussions about end-of-life care and advance care planning are dealt with sensitively and when appropriate for each family, in the case of HGG it may be helpful to have these discussions early in the disease trajectory, before cognitive changes and communication difficulties make dialogue more difficult. Having these discussions may assist caregivers in their role as proxy decision-makers.

\section{Study limitations}

Participants were recruited from a single site; however, this site treats most neurological cancers in Western Australia. The use of purposive sampling to identify participants with differing clinical and social situations and at different points in the disease trajectory ensured a more complete understanding of caregiver needs. Further research is required to determine how caregiver needs change over time as the condition of the person they are caring for deteriorates. Future research by the authors will use quantitative methods to ascertain these needs.

\section{Conclusions}

A diagnosis of HGG brings a period of rapid change for caregivers. Adequate support is required throughout the illness to assist caregivers to manage this devastating disease. In particular, ensuring appropriate information is readily available for caregivers and that they can access support for their decision-making role are crucial.

\section{Acknowledgements}

This project was funded by an unrestricted educational grant from Schering Plough Lty Ptd. The authors wish to thank Sky Dawson, Jennifer Clarke and Sylvia Heavens for assisting with data collection for this study and Sky Dawson and Amy Hingston for their participation in coding the transcripts.

\section{References}

1. Krex D, Klink B, Hartmann C, et al. Long-term survival with glioblastoma multiforme. Brain 2007; 130: 2596-2606.

2. Rampling R, James A, Papanastassiou V. The present and future management of malignant brain tumours: surgery, radiotherapy, chemotherapy. $J$ Neurol Neurosurg Psychiatry 2004; 75(Suppl II): ii24-ii30.

3. Osoba DM, Brada M, Prados MD, Yung WK. Effect of disease burden on health-related quality of life in patients with malignant gliomas. Neuro-Oncology 2000; 2: 221-228.

4. McNamara S. An overview of palliative care for patients with brain tumours: an interprofessional approach. $\mathrm{Br} \mathrm{J}$ Neurosci Nurs 2008; 4: 435-437.

5. Catt S, Chalmers A, Fallowfield L. Psychosocial and supportive-care needs in high-grade glioma. Lancet Oncol 2008; 9: 884-891.

6. Davies E, Higginson IJ. Communication, information and support for adults with malignant cerebral glioma: a systematic literature review. Support Care Cancer 2003; 11: 21-29.

7. Sherwood PR, Given BA, Doorenbos AZ, Given CW. Forgotten voices: lessons from bereaved caregivers of persons with a brain tumour. Int $J$ Palliat Nurs 2004; 10: $67-75$. 
8. Schmer C, Ward-Smith P, Latham S, Salacz M. When a family member has a malignant brain tumour: the caregiver perspective. J Neurosci Nurs 2008; 40: 78-84.

9. Keir ST. Levels of stress and intervention preferences of caregivers of brain tumour patients. Cancer Nurs 2007; 30: E33-E39.

10. Janda M, Eakin EG, Bailey L, Walker D, Troy K. Supportive care needs of people with brain tumours and their caregivers. Support Care Cancer 2006; 14: 1094-1103.

11. Muñoz C, Juarez G, Muñoz ML. The quality of life of patients with malignant gliomas and their caregivers. Soc Work Health Care 2008; 47: 455-478.

12. Lipsman N, Skanda A, Kimmelman J, Bernstein M. The attitudes of brain cancer patients and their caregivers towards death and dying: a qualitative study. $B M C$ Palliat Care 2007; 6: 7.

13. Given B, Wyatt G, Given C, et al. Burden and depression among caregivers of patients with cancer at the end of life. Oncol Nurs Forum 2004; 31: 1105-1117.

14. Glaser B, Strauss A. The discovery of grounded theory. London: Weidenfled \& Nicholson, 1967.

15. Spradley JP. Participant observation. New York: Holt, Rinehart \& Winston, 1980.
16. Halkett GKB, Lobb EA, Oldham L, Nowak A. The information and support needs of patients diagnosed with High Grade Glioma. Patient Educ Couns 2009; Sep 15. [Epub ahead of print] doi:10.1016/j.pec.2009.08.013.

17. Braun M, Mikulincer M, Rydall A, Walsh A, Rodin G. Hidden morbidity in cancer: spouse caregivers. J Clin Oncol 2007; 25: 4829-4834.

18. Kim Y, Schulz R. Family caregivers' strains comparative analysis of cancer caregiving with dementia, diabetes, and frail elderly caregiving. J Aging Health 2008; 20: 483-503.

19. Mangan PA, Taylor KL, Yabroff KR, Fleming DA, Ingham JM. Caregiving near the end of life: unmet needs and potential solutions. Palliat Support Care 2003; 1: 247-259.
20. Grunfeld E, Coyle D, Whelan T, et al. Family caregiver burden: results of a longitudinal study of breast cancer patients and their principal caregivers. CMAJ 2004; 170: 1811-1812.

21. Jo S, Brazil K, Lohfeld L, Willison K. Caregiving at the end of life: perspectives from spousal caregivers and care recipients. Palliat Support Care 2007; 5: 11-17.

22. Clemmer SJ, Ward-Griffin C, Forbes D. Family members providing home-based palliative care to older adults: the enactment of multiple roles. Can J Aging 2008; 27: 267-283.

23. Schubart JR, Kinzie MB, Farace E. Caring for the brain tumour patient: family caregiver burden and unmet needs. Neuro-oncology 2007; 10: 61-72.

24. Dubenske LI, Wen KY, Gustafson DH, et al. Caregivers' differing needs across key experiences of the advanced cancer disease trajectory. Palliat Support Care 2008; 6: 265-272.

25. Cashman R, Bernstein LJ, Bilodeau D, et al. Evaluation of an educational program for the caregivers of persons diagnosed with a malignant glioma. Can Oncol Nurs $J$ 2007; 17: 6-10.

26. Spetz A, Henriksson R, Salandar P. A specialist nurse as a resource for family members to patients with brain tumours: an action research study. Cancer Nurs 2008; 31: E18-E26.

27. Spetz A, Henriksson R, Bergenheim AT, Salandar P. A specialist nurse-function in neuro-oncology: a qualitative study of possibilities, limitations, and pitfalls. Palliat Support Care 2005; 3: 121-130.

28. Curren JR. Support needs of brain tumour patients and their carers: the place of a telephone service. Int $J$ Palliat Nurs 2001; 7: 331-337.

29. Greaves J, Vojkovic S, Nikoletti S, White K, Yuen K. Family caregivers' perceptions and experiences of delirium in patients with advanced cancer. Aust J Cancer Nurs 2008; 9: 2-10. 